\title{
Review
}

\section{Epidemiology and Clinical Phenotypes and Presentations of Neonatal Diabetes}

Mohammed Babonji ${ }^{1}$, Khawla Kalantan ${ }^{2}$, Fadih Alenezi ${ }^{3}$, Reham Alruwaili ${ }^{3}$, Elham Bantan ${ }^{2}$, Rasha Al Saleh ${ }^{4}$, Noor Abdulrahim $^{5}$, Reema Abuyabis ${ }^{6}$, Zahraa Alsarefi ${ }^{7}$, Waad Aljubairah ${ }^{8}$, Zohor Alamri ${ }^{9}$, Abdulghani Alzamzami ${ }^{1}$, Raed Alsamadani ${ }^{1}$

${ }^{1}$ Department of Pediatrics, Al Aziziyah Children Hospital, Jeddah, Saudi Arabia

${ }^{2}$ Department of Pediatrics, Maternity and Children Hospital, Mecca, Saudi Arabia

${ }^{3}$ College of Medicine, Norhtern Border University, Arar, Saudi Arabia

${ }^{4}$ College of Medicine, King Khalid University, Abha, Saudi Arabia

${ }^{5}$ College of Medicine, Batterjee Medical College, Jeddah, Saudi Arabia

${ }^{6}$ College of Medicine, Umm Al-Qura University, Mecca, Saudi Arabia

${ }^{7}$ College of Medicine, Medical University of Warsaw, Warsaw, Poland

${ }^{8}$ Department of Pediatrics, Maternity and Children Hospital, Al-Ahsaa, Saudi Arabia

${ }^{9}$ Department of Emergency Medicine, Aseer Central Hospital, Abha, Saudi Arabia

Correspondence should be addressed to Mohammed Babonji, Department of Pediatrics, Al Aziziyah Children Hospital, Jeddah, Saudi Arabia, Email: dr.mohammed_babonji1406@hotmail.com

Received: 8 September 2021, Revised: 10 September 2021, Accepted: 12 September 2021, Published: 14 September 2021

Copyright (C) 2021 Babonji et al. This is an open access article distributed under the Creative Commons Attribution License, which permits unrestricted use, distribution, and reproduction in any medium, provided the original work is properly cited.

\begin{abstract}
Neonatal diabetes mellitus is a rare condition that develops within the first months of life, usually as a result of a genetic abnormality. The condition has been defined as the presence of a severe form of hyperglycemia that requires adequate management and usually affected neonates and young infants. The disease has also been divided into two or three categories, upon which the clinical presentations of the affected patients usually depend. In the present study, we have reviewed the current literature to discuss the epidemiology, clinical phenotypes and presentations of patients suffering from neonatal diabetes. The condition is a rare one and some of the proposed etiologies may include a stress-related increase in the levels of counter-regulatory hormones, sepsis, and the increased or improper parenteral administration of $\beta$-adrenergic agents, steroids, or glucose. Three main categories have been identified for neonatal diabetes, including transient, permanent, and syndromic diabetes, which vary based on the underlying genetic mutations. Various developmental and neurological disorders have been linked with the disease. Therefore, planning adequate interventions as early as possible is critical to enhancing the outcomes as some affected children are prone to depend on insulin therapy throughout their entire life.
\end{abstract}

Keywords: - Neonatal diabetes, diabetes mellitus, epidemiology, clinical presentation, genetics. 


\section{Journal of Healthcare Sciences}

\section{Introduction}

Neonatal diabetes mellitus is a rare condition that develops within the first months of life, usually as a result of a genetic abnormality (1-3). The incidence of the disease has been estimated to be very low, and epidemiological studies indicate that such rates are hugely variable among different ethnic groups. The condition has been defined as the presence of a severe form of hyperglycemia that requires adequate management and usually affects neonates and young infants. In a previous investigation conducted in Finland, the authors followed infants with neonatal diabetes for six months and found that these children had significantly higher circulating number of autoantibodies against the is lets cells of the pancreas, in addition to an increase in risk of HLA genotypic overexpression. Therefore, the authors concluded that the disease may be associated with an autoimmune characteristic (4). Evidence also indicates that in addition to the characteristic hyperglycemia, the condition is usually associated with reduced amounts of insulin synthesis/release (2). The disease has also been divided into two or three categories, upon which the clinical presentations of the affected patients usually depend $(5,6)$. Accordingly, in the present study, we aim to review the current literature to discuss the epidemiology, clinical phenotypes and presentations of patients suffering from neonatal diabetes.

\section{Methods}

This literature review is based on an extensive literature search in the Medline, Cochrane, and EMBASE databases which was performed on 27 August, 2021, using the medical subject headings (MeSH) or a combination of all possible related terms $(7,8)$. Papers discussing patients suffering from neonatal diabetes were screened for relevant information, with no limitation placed on date, language, age of participants, or publication type.

\section{Epidemiology}

Many investigations have estimated the prevalence of neonatal diabetes mellitus. These studies indicate that the disease is very rare and occurs within the first six months of life. The estimated incidence rate ranges between 1 every 90,000-160,000 live births $(9,10)$.
Neonatal diabetes is usually attributable to a monogamic cause that eventually leads to the development of other types of diabetes. Many reasons have been attributed to the development of hyperglycemia in this population. Some of these etiologies may include a stress-related increase in the levels of counter-regulatory hormones, sepsis, and the increased or improper parenteral administration of $\beta$-adrenergic agents, steroids, or glucose. It has been demonstrated that hyperglycemia, however, is not a rare presentation in this population (11).

Accordingly, to diagnose neonatal diabetes in infancy is considered a difficult approach. Epidemiological studies also indicate that this hyperglycemia can persist for up to 10 days. However, in most cases, it has been observed that the hyperglycemia is transient and rapidly resolves within 2-3 days after it has developed within the 3-5 first days of the neonatal life. Moreover, it was further demonstrated that the difficulty in diagnosis is even more so in lowbirth-weight infants and the preterm population (12-14). A prevalence rate of $25-75 \%$ has been estimated for the low-birth-weight infants that suffer from hyperglycemia $(11,12,15)$. It has been further indicated that a degree of relative insulin resistance and reduced secretion of insulin from the pancreatic cells has been observed in some critically ill low-birth-weight infants (11). On the other hand, Besser et al. conducted a recent investigation in 2016 and included 750 infants who were diagnosed with diabetes with onset before they were six months old. Among this population, the authors reported that 604 patients were born at $\geq 37$ gestational weeks, while the rest $(n=146)$ were born at $<37$ gestational weeks.

The same study also reported that the prevalence of a genetic etiology was $66 \%(97 / 146)$ in the preterm population (<37 gestational weeks) compared to $83 \%$ (501/604) in the other group ( $\geq 37$ gestational weeks). Additionally, it has been demonstrated that the prevalence of the genetic etiology was higher in the latter group $(83 \%)$ when compared to neonates that were born at 32$<37$ weeks of gestation $(81 \%)$, and significantly more than others that were born at $<37$ gestational weeks (31\%). Finally, the authors also estimated that no significant difference was noticed between preterm and full-term infants at presentation in terms of age, which was 1 versus 0.7 weeks for both groups, respectively (12). 
Based on these findings, it can be concluded that to adequately diagnose neonatal diabetes, the diagnosis should be established in the presence of insulin-dependent hyperglycemia.

\section{Clinical Presentations}

Regarding the duration of insulin dependency in the affected children, evidence shows that there are two main clinical presentations of neonatal diabetes: a transient form, and a permanent one. In the permanent form, it has been reported that the treatment of the disease is based on life-long modalities, unlike the transient form which usually requires the administration of a treatment plan for the first weeks of life, but may only extend to 5 years of age for the affected child (16). Additionally, it has been demonstrated that the clinical presentations of the two types of neonatal diabetes are not significantly dependent on the underlying molecular mechanisms and associated characteristics. For instance, it has been demonstrated that $\mathrm{KCNJ}_{11}, \mathrm{ABCC} 8$, and INS genetic mutations have been associated with both transient and permanent clinical forms (17-20).

However, it has been demonstrated that the permanent type is usually associated with other genetic mutations. Diagnosis of neonatal diabetes is usually established within the first six months of life. However, it has been reported that the genetic cause can significantly affect the age of diagnosis of the disease. For instance, it has been demonstrated that in $100 \%$ and $93 \%$ of the cases with 6q24 locus abnormalities, the diagnosis of neonatal diabetes is established before 3 and 1 months of age, respectively. Moreover, it was also estimated that in $66 \%$, and $30 \%$ of cases with $\mathrm{KCNJ}_{11}$ and $\mathrm{ABCC} 8$ genetic mutations, the diagnosis of neonatal diabetes is usually established before one and six months of age, respectively (16). A low-birth-weight that is usually below the 10th percentile is also another clinical characteristic that can be observed in $62 \%$ of cases with neonatal diabetes at birth, which indicates the critical value of insulin in the proper neonatal growth and development. It has been further demonstrated that all of the affected patients usually suffer from intrauterine growth retardation, and it has been estimated that the impact is significantly greater in the population with $6 \mathrm{q} 24$ abnormalities than the $\mathrm{KCNJ}_{11}$ and $\mathrm{ABCC} 8$ genetic mutations groups (16).
Remission from diabetes has also been reported to affect approximately $50 \%$ of cases with a detectable pancreas using ultrasound modalities, and such events have been determined to occur within the first four months of age $(16,21-23)$.

A recent long follow-up investigation also indicated that patients with transient type neonatal diabetes have been observed to suffer from a significant reduction in the pancreatic insulin mass, which was indicated by the reduced secretion of insulin in response to arginine and glucose stimulatory secretions. Moreover, it has been demonstrated that these children usually suffer from school learning difficulties, irrespective of the duration of diabetes and the underlying genetic abnormality. Therefore, it has been demonstrated that close monitoring should be undertaken for the blood glucose levels, $\mathrm{HbA1C}$, and neurodevelopmental functions of these children in order to enhance the associated outcomes (24). In general, developmental defects and neurological disorders have been associated with patients suffering from neonatal diabetes with a sound pancreatic structure (24). It has been reported that in approximately $25 \%$ of cases with $\mathrm{KCNJ}_{11}$ and $\mathrm{ABCC} 8$ genetic abnormalities, many neurodevelopmental functions are usually impaired, including reduced cognition development, and psychomotor functional abnormalities (23).

A previous investigation also indicated that all of the cases with neonatal diabetes usually suffered from attention-deficit disorders and/or language-related conditions that may even develop into dyslexia, when these patients are assessed for their neurodevelopmental functions (16). Other manifestations can also include umbilical hernia, macroglossia, urinary and renal malformations, cardiac malformations, hypothyroidism, and non-autoimmune anemia, in addition to other neurological abnormalities which have been reportedly associated with patients suffering from 6q24 locus abnormalities $(16,25)$. However, it has also been reported that in cases of $\beta$ cell dysfunction and/or abnormal pancreatic morphology, the clinical presentations that include the developmental and neurological abnormalities include a variety of syndromes that significantly depend on the underlying genetic abnormality. Syndromic neonatal diabetes will be discussed in the following section. 


\section{Clinical Phenotypes}

Three categories have been identified in the literature as the main clinical phenotypes of neonatal diabetes. Furthermore, these categories include permanent diabetes, which is characterized by absence of remission and being isolated in its presentation, the transient one, which is characterized by remission and relapse, and the syndromic category, which is usually identified as a part of a present syndrome affecting the patient. It has been estimated that the prevalence of transient neonatal diabetes has been previously reported to be $20 \%$ among patients with neonatal diabetes (26). Permanent diabetes is usually attributable to the presence of $\mathrm{KCNJ}_{11}$ and ABCC8 genetic abnormalities, as it has been observed in approximately half of the affected patients $(13,27)$. These mutations were also reported to proceed the transient type, being the second most common etiologies. It has been estimated that the median age for the presentation of the affected infants is 9.6 weeks (28).

Additionally, most patients usually present before six months of age while only a few presents after this age. It has been demonstrated that patients with $\mathrm{KCNJ}_{11}$ tend to have higher frequencies of neurocognitive disorders, sleep disturbances, reduced developmental, social, and learning abilities, as a result of being more liable to develop attention deficit hyperactivity disorder. The Developmental Delay, Epilepsy, and Neonatal Diabetes syndrome (DEND) may also be a characteristic in patients with significant $\mathrm{KCNJ}_{11}$ mutations (23, 29-31). Mutations in the INS gene are also another common cause that may attribute to the development of permanent neonatal diabetes, with a median age of 10 weeks at presentation. Additionally, it has been estimated that less than one-third of the affected population usually suffer from diabetic ketoacidosis. Lifelong management with insulin is indicated for these patients, however, neonatal diabetes is the only observed abnormality in these patients $(32,33)$. In transient neonatal diabetes, the pathology usually resolves within weeks after diagnosis. However, it has been estimated that these children are more prone to develop diabetes later on in their lives $(13,26,34)$. The most common cause for this category has been reported to be a $6 q 24$ locus genetic abnormality $(13,35,36)$.

Furthermore, previous studies indicate that patients with these abnormalities usually develop neonatal diabetes before other patients with $\mathrm{KCNJ}_{11}$ and ABCC8 genetic abnormalities.
Umbilical hernia and macroglossia may also be associated with these patients. Early treatment of these patients requires the administration of insulin. However, noninsulin modalities can be used later on as in the case with type 2 diabetes mellitus (37). A previous investigation estimated that 14 of these patients usually suffer from hypoglycemia following remission of the pathology. Abnormalities to the genes that control insulin release from the pancreas via the voltage-dependent potassium channels (including the $\mathrm{KCNJ}_{11}$ and $\mathrm{ABCC} 8$ genes) may also attribute to the development of hyperglycemia (transient neonatal diabetes) $(13,26)$. As previously mentioned, syndromic neonatal diabetes may be involved in a variety of syndromes. The main reason that attributes to the development of diabetes is the involvement of a pancreatic pathology in syndromes associated with neonatal diabetes, which will eventually affect insulin synthesis and/or release. Estimates show that WolcottRallison syndrome is the most common syndrome, which is also associated with skeletal dysplasia, and hepatic dysfunction (38). Other syndromes may also include Fanconi Bickel syndrome, IPEX syndrome, Wolfram syndrome, Rogers syndrome, and Rabson-Mendenhall syndrome (Figure 1) $(13,39)$.

\begin{tabular}{|c|c|}
\hline $\begin{array}{c}\text { Transient neonatal diabetes } \\
\text { mellitus }\end{array}$ & $\begin{array}{c}\text { Permanent neonatal diabetes } \\
\text { mellitus }\end{array}$ \\
\hline $\begin{array}{ll} & \text { Chromosomes } 6 \\
& \text { anomalies detected }\end{array}$ & $\begin{array}{l}\text { - Heterozygous activating } \\
\text { mutation in } K C N J 11 \text { gene and in } \\
A B C C 8 \text { gene (Kir6.2 and SUR1 } \\
\text { subunits of the pancreatic } \mathrm{K}_{\text {atp }} \\
\text { channel) }\end{array}$ \\
\hline $\begin{array}{ll}\text { - } & \text { Paternal } \\
& \text { duplications }\end{array}$ & \\
\hline - $\quad$ Paternal isodisomy & \\
\hline - $\quad$ Methylation defect & \\
\hline $\begin{array}{ll}- & \mathrm{ABCC} 8 \text { (SUR1) and } \\
\text { rarely KCNJ11 (Kir6.2) } \\
\text { mutations }\end{array}$ & $\begin{array}{l}\text { - IPEX Syndrome: diffuse } \\
\text { autoimmunity } \\
\text { - Mitochondrial disease } \\
\text { - Severe pancreatic hypoplasia } \\
\text { associated with IPF1 (PDX1) } \\
\text { mutation } \\
\text { - Homozygous glucokinase } \\
\text { mutation: insensitivity to glucose } \\
\text { - Associated with epiphyseal } \\
\text { dysplasia: Wolcott Rallison } \\
\text { Syndrome } \\
\text { - Possibly associated with } \\
\text { enterovirus infection } \\
\text { - Association with cerebellar } \\
\text { hypoplasia and PTF1A mutation } \\
\text { - Association with } \\
\text { hypothyroidism, glaucoma and } \\
\text { GLIS3 mutation }\end{array}$ \\
\hline
\end{tabular}

Figure 1. Different etiologies of neonatal diabetes mellitus (6). 


\section{Conclusion}

Neonatal diabetes is a rare disorder with some of the proposed etiologies may include a stress-related increase in the levels of counter-regulatory hormones, sepsis, and the increased or improper parenteral administration of $\beta$ adrenergic agents, steroids, or glucose. Three main categories have been identified for neonatal diabetes, including transient, permanent, and syndromic diabetes, which vary based on the underlying genetic mutations. Various developmental and neurological disorders have been linked with the disease. Therefore, planning adequate interventions as early as possible is critical to enhancing the outcomes as some affected children are prone to depend on insulin therapy throughout their entire life.

\section{Disclosure}

\section{Statement:}

The authors declare no conflict of interest.

\section{Funding:}

None.

\section{Ethical Consideration:}

Non applicable.

\section{Data Availability:}

All data are presented within the paper.

\section{References}

1. Kanakatti Shankar R, Pihoker C, Dolan LM, Standiford D, Badaru A, Dabelea D, et al. Permanent neonatal diabetes mellitus: prevalence and genetic diagnosis in the SEARCH for Diabetes in Youth Study. Pediatric diabetes. 2013;14(3):174-80.

2. Polak M, Cavé H. Neonatal diabetes mellitus: a disease linked to multiple mechanisms. Orphanet journal of rare diseases. 2007;2:12.
3. Iafusco D, Massa O, Pasquino B, Colombo C, Iughetti $\mathrm{L}$, Bizzarri $\mathrm{C}$, et al. Minimal incidence of neonatal/infancy onset diabetes in Italy is 1:90,000 live births. Acta diabetologica. 2012;49(5):405-8.

4. Huopio H, Miettinen PJ, Ilonen J, Nykänen P, Veijola R, Keskinen P, et al. Clinical, Genetic, and Biochemical Characteristics of Early-Onset Diabetes in the Finnish Population. The Journal of clinical endocrinology and metabolism. 2016;101(8):3018-26.

5. Beltrand J, Busiah K, Vaivre-Douret L, Fauret AL, Berdugo M, Cavé H, et al. Neonatal Diabetes Mellitus. Frontiers in Pediatrics. 2020;8(602).

6. Polak M, Cavé H. Neonatal diabetes mellitus: a disease linked to multiple mechanisms. Orphanet journal of rare diseases. 2007;2(1):12.

7. Ghozy S, Tran L, Naveed S, Quynh TTH, Helmy Zayan A, Waqas A, et al. Association of breastfeeding status with risk of autism spectrum disorder: A systematic review, dose-response analysis and meta-analysis. Asian J Psychiatr. 2020;48:101916.

8. Mahmoud AR, Dahy A, Dibas M, Abbas AS, Ghozy S, El-Qushayri AE. Association between sarcoidosis and cardiovascular comorbidity: A systematic review and meta-analysis. Heart Lung. 2020;49(5):512-7.

9. Grulich-Henn J, Wagner V, Thon A, Schober E, Marg W, Kapellen TM, et al. Entities and frequency of neonatal diabetes: data from the diabetes documentation and quality management system (DPV). Diabetic medicine : a journal of the British Diabetic Association. 2010;27(6):709-12.

10. Nansseu JR, Ngo-Um SS, Balti EV. Incidence, prevalence and genetic determinants of neonatal diabetes mellitus: a systematic review and meta-analysis protocol. Systematic reviews. 2016;5(1):188.

11. Beardsall K, Vanhaesebrouck S, Ogilvy-Stuart AL, Vanhole C, Palmer CR, Ong K, et al. Prevalence and determinants of hyperglycemia in very low birth weight infants: cohort analyses of the NIRTURE study. The Journal of pediatrics. 2010;157(5):715-9.e1-3.

12. Besser RE, Flanagan SE, Mackay DG, Temple IK, Shepherd MH, Shields BM, et al. Prematurity and Genetic Testing for Neonatal Diabetes. Pediatrics. 2016;138(3). 
13. Lemelman MB, Letourneau L, Greeley SAW. Neonatal Diabetes Mellitus: An Update on Diagnosis and Management. Clinics in perinatology. 2018;45(1):41-59.

14. Thieu H, Bach Dat B, Nam NH, Reda A, Duc NT, Alshareef A, et al. Antibiotic resistance of Helicobacter pylori infection in a children's hospital in Vietnam: prevalence and associated factors. Minerva medica. 2020;111(5):498-501.

15. Sabzehei MK, Afjeh SA, Shakiba M, Alizadeh P, Shamshiri AR, Esmaili F. Hyperglycemia in VLBW infants; incidence, risk factors and outcome. Archives of Iranian medicine. 2014;17(6):429-34.

16. Busiah K, Drunat S, Vaivre-Douret L, Bonnefond A, Simon A, Flechtner I, et al. Neuropsychological dysfunction and developmental defects associated with genetic changes in infants with neonatal diabetes mellitus: a prospective cohort study. The lancet Diabetes \& endocrinology. 2013;1(3):199-207.

17. Babenko AP, Polak M, Cavé H, Busiah K, Czernichow P, Scharfmann R, et al. Activating mutations in the ABCC 8 gene in neonatal diabetes mellitus. The New England journal of medicine. 2006;355(5):456-66.

18. Bonnefond A, Lomberk G, Buttar N, Busiah K, Vaillant E, Lobbens S, et al. Disruption of a novel Kruppel-like transcription factor p300-regulated pathway for insulin biosynthesis revealed by studies of the c.-331 INS mutation found in neonatal diabetes mellitus. The Journal of biological chemistry. 2011;286(32):28414-24.

19. Støy J, Edghill EL, Flanagan SE, Ye H, Paz VP, Pluzhnikov A, et al. Insulin gene mutations as a cause of permanent neonatal diabetes. Proceedings of the National Academy of Sciences of the United States of America. 2007;104(38):15040-4.

20. El-Qushayri AE, Dahy A, Reda A, Mahmoud MA, Abdel Mageed S, Kamel AMA, et al. A closer look to the high burden of the psychiatric disorders among health care workers (HCWs) in Egypt during COVID-19 outbreak: A meta-analysis of $3137 \mathrm{HCWs}$. Epidemiology and health. 2021:e2021045.

21. Garin I, Edghill EL, Akerman I, Rubio-Cabezas O, Rica I, Locke JM, et al. Recessive mutations in the INS gene result in neonatal diabetes through reduced insulin biosynthesis. Proceedings of the National Academy of Sciences of the United States of America. 2010;107(7):3105-10.
22. Gloyn AL, Reimann F, Girard C, Edghill EL, Proks P, Pearson ER, et al. Relapsing diabetes can result from moderately activating mutations in $\mathrm{KCNJ}_{11}$. Human molecular genetics. 2005;14(7):925-34.

23. Amiel SA, Caprio S, Sherwin RS, Plewe G, Haymond MW, Tamborlane WV. Insulin resistance of puberty: a defect restricted to peripheral glucose metabolism. The Journal of clinical endocrinology and metabolism. 1991;72(2):277-82.

24. Le Bourgeois F, Beltrand J, Baz B, Julla JB, Riveline JP, Simon A, et al. Long-term Metabolic and Socioeducational Outcomes of Transient Neonatal Diabetes: A Longitudinal and Cross-sectional Study. Diabetes Care. 2020;43(6):1191-9.

25. Docherty LE, Kabwama S, Lehmann A, Hawke E, Harrison L, Flanagan SE, et al. Clinical presentation of 6q24 transient neonatal diabetes mellitus (6q24 TNDM) and genotype-phenotype correlation in an international cohort of patients. Diabetologia. 2013;56(4):758-62.

26. De Franco E, Flanagan SE, Houghton JA, Lango Allen H, Mackay DJ, Temple IK, et al. The effect of early, comprehensive genomic testing on clinical care in neonatal diabetes: an international cohort study. Lancet (London, England). 2015;386(9997):957-63.

27. Rafiq M, Flanagan SE, Patch AM, Shields BM, Ellard S, Hattersley AT. Effective treatment with oral sulfonylureas in patients with diabetes due to sulfonylurea receptor 1 (SUR1) mutations. Diabetes Care. 2008;31(2):204-9.

28. Letourneau LR, Carmody D, Wroblewski K, Denson AM, Sanyoura M, Naylor RN, et al. Diabetes Presentation in Infancy: High Risk of Diabetic Ketoacidosis. Diabetes Care. 2017;40(10):e147-e8.

29. Fujimura N, Tanaka E, Yamamoto S, Shigemori M, Higashi H. Contribution of ATP-sensitive potassium channels to hypoxic hyperpolarization in rat hippocampal CA1 neurons in vitro. Journal of neurophysiology. 1997;77(1):378-85.

30. Carmody D, Pastore AN, Landmeier KA, Letourneau LR, Martin R, Hwang JL, et al. Patients with $\mathrm{KCNJ}_{11^{-}}$ related diabetes frequently have neuropsychological impairments compared with sibling controls. Diabetic medicine : a journal of the British Diabetic Association. 2016;33(10):1380-6. 


\section{Journal of Healthcare Sciences}

31. Landmeier KA, Lanning M, Carmody D, Greeley SAW, Msall ME. ADHD, learning difficulties and sleep disturbances associated with $\mathrm{KCNJ}_{11}$-related neonatal diabetes. Pediatric diabetes. 2017;18(7):518-23.

32. Edghill EL, Flanagan SE, Patch AM, Boustred C, Parrish A, Shields B, et al. Insulin mutation screening in 1,044 patients with diabetes: mutations in the INS gene are a common cause of neonatal diabetes but a rare cause of diabetes diagnosed in childhood or adulthood. Diabetes. 2008;57(4):1034-42.

33. Dimova R, Tankova T, Gergelcheva I, Tournev I, Konstantinova M. A family with permanent neonatal diabetes due to a novel mutation in INS gene. Diabetes Res Clin Pract. 2015;108(2):e28-30.

34. Rubio-Cabezas O, Ellard S. Diabetes mellitus in neonates and infants: genetic heterogeneity, clinical approach to diagnosis, and therapeutic options. Hormone research in paediatrics. 2013;80(3):137-46.

35. Temple IK, Shield JP. Transient neonatal diabetes, a disorder of imprinting. Journal of medical genetics. 2002;39(12):872-5.
36. Mackay DJ, Callaway JL, Marks SM, White HE, Acerini CL, Boonen SE, et al. Hypomethylation of multiple imprinted loci in individuals with transient neonatal diabetes is associated with mutations in ZFP57. Nature genetics. 2008;40(8):949-51.

37. Flanagan SE, Mackay DJ, Greeley SA, McDonald TJ, Mericq V, Hassing J, et al. Hypoglycaemia following diabetes remission in patients with 6q24 methylation defects: expanding the clinical phenotype. Diabetologia. 2013;56(1):218-21.

38. Delépine M, Nicolino M, Barrett T, Golamaully M, Lathrop GM, Julier C. EIF2AK3, encoding translation initiation factor 2-alpha kinase 3, is mutated in patients with Wolcott-Rallison syndrome. Nature genetics. 2000;25(4):406-9.

39. Hattersley A, Bruining J, Shield J, Njolstad P, Donaghue K. ISPAD Clinical Practice Consensus Guidelines 2006-2007. The diagnosis and management of monogenic diabetes in children. Pediatric diabetes. 2006;7(6):352-60. 